\title{
Profiles and drivers of antibiotic resistance genes distribution in one-stage and two-stage sludge anaerobic digestion based on microwave- $\mathrm{H}_{2} \mathrm{O}_{2}$ pretreatment
}

\author{
Junya Zhang ${ }^{\mathrm{a}, \mathrm{b}, \mathrm{c}, 1}$, Jibao Liu ${ }^{\mathrm{d}, 1}$, Yawei Wang ${ }^{\mathrm{a}, \mathrm{b}, \mathrm{c}}$, Dawei Yu ${ }^{\mathrm{a}, \mathrm{b}, \mathrm{c}}$, Qianwen Sui ${ }^{\mathrm{a}, \mathrm{b}, \mathrm{c}}$, Rui Wang ${ }^{\mathrm{a}, \mathrm{b}, \mathrm{c}}$, \\ Meixue Chen $^{\text {a,b,c }}$, Juan Tong ${ }^{\text {a,b,c }}$, Yuansong Wei ${ }^{\text {a,b,c,* }}$
}

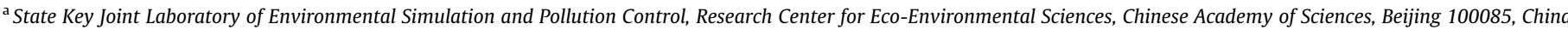

${ }^{\mathrm{b}}$ Department of Water Pollution Control Technology, Research Center for Eco-Environmental Sciences, Chinese Academy of Sciences, Beijing 100085, China

${ }^{\mathrm{c}}$ University of Chinese Academy of Sciences, Beijing 100049, China

${ }^{\mathrm{d}}$ School of Environmental and Chemical Engineering, Tianjin Polytechnic University, Tianjin 300387, China

\section{H I G H L I G H T S}

- Pretreatment with subsequent anaerobic digestion enhanced ARGs abundance reduction.

- Two-stage system showed some advantages over the ARGs abundance reduction.

- Anaerobic digestion was more effective on pathogens control than pretreatment.

- Changes of bacterial community was significantly correlated with ARGs profiles.

- Anaerobic digestion was a potential technology for ARGs control.

\section{A R T I C L E I N F O}

\section{Article history:}

Received 23 March 2017

Received in revised form 24 May 2017

Accepted 25 May 2017

Available online 29 May 2017

\section{Keywords:}

Antibiotic resistance genes

Waste activated sludge

Co-selection from heavy metals

Microwave pretreatment

Two-stage anaerobic digestion
G R A P H I C A L A B S T R A C T

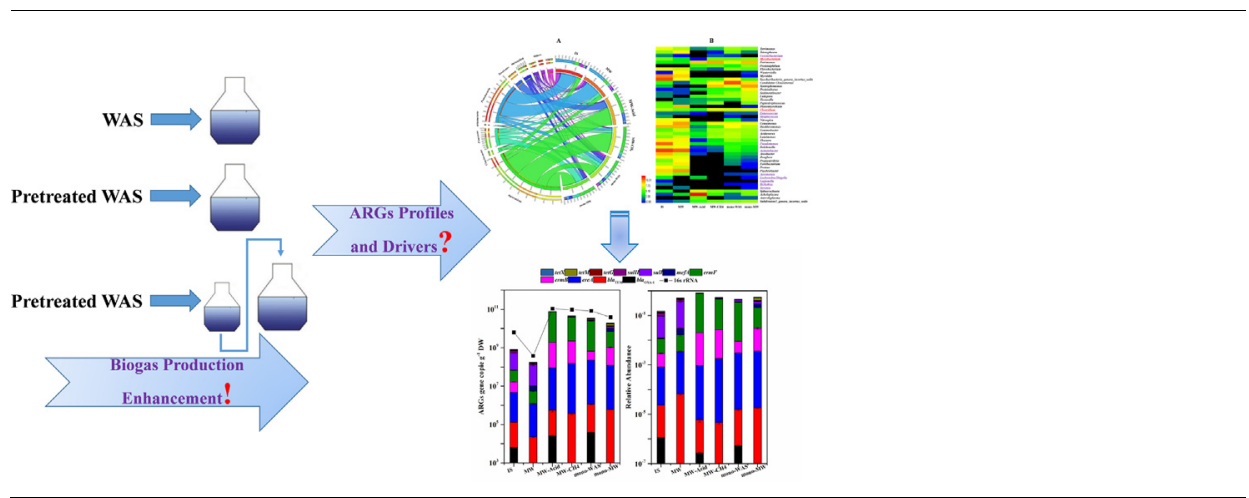

\begin{abstract}
A B S T R A C T
Three anaerobic digestion (AD) processes of waste activated sludge (WAS) were established including the control (mono-WAS), one-stage $\mathrm{AD}$ and two-stage $\mathrm{AD}$ along with microwave- $\mathrm{H}_{2} \mathrm{O}_{2}$ pre-treatment (MW$\mathrm{H}_{2} \mathrm{O}_{2}$ ) to investigate the profiles and drivers of antibiotic resistance genes (ARGs) distribution concerning co-selection from heavy metals, intI1 and microbial community through qPCR and high-throughput sequencing method. Results showed that $\mathrm{MW}-\mathrm{H}_{2} \mathrm{O}_{2}$ could reduce the absolute gene copies of all ARGs while increased the relative abundance of most ARGs. After subsequent AD, both total ARGs quantities and relative abundance were enriched while two-stage AD showed some advantages over ARGs abundance reduction. Besides, AD was more effective on the potential pathogens reduction than $\mathrm{MW}-\mathrm{H}_{2} \mathrm{O}_{2}$. AD could reduce the role of intI1 on the spread of ARGs, while mantel test and procrustes analysis indicated that the variation of ARGs abundance was closely associated with the discrepancy of bacterial community.
\end{abstract}

() 2017 Elsevier Ltd. All rights reserved.

Abbreviations: ARGs, antibiotic resistance genes; ARB, antibiotic resistance bacteria; AD, anaerobic digestion; WAS, waste activated sludge; MW, microwave pretreatment;

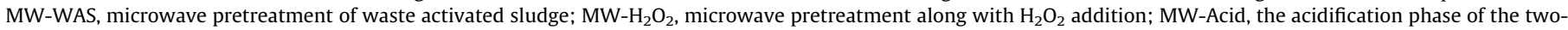
stage anaerobic digestion; $\mathrm{MW}-\mathrm{CH}_{4}$, the methane-producing phase of the two-stage anaerobic digestion; WWTPs, wastewater treatment plants.

* Corresponding author.

E-mail address: yswei@rcees.ac.cn (Y. Wei).

${ }^{1}$ Junya Zhang and Jibao Liu contributed equally to this work. 


\section{Introduction}

The rapid spread of antibiotic resistance bacteria (ARB) indicated that we were close to a point where we may not be able to prevent or treat everyday infections or diseases (United Kingdom Department of Health \& DEFRA, 2013). Antibiotic resistance genes (ARGs), as the culprit of bacterial resistance to antibiotics, were gradually consider to be an emerging pollutant in the environment, and municipal wastewater treatment plants (WWTPs) become one of the most important reservoirs of ARGs (Mao et al., 2015), and antibiotic resistance factors from WWTPs have been demonstrated to be associated with clinical pathogens (Kumaraswamy et al., 2014; Su et al., 2015). Waste activated sludge (WAS), as the byproduct of the WWTPs, contained high amounts of ARB and ARGs, and 6.25 million tons of dry WAS were produced in 2013 in China, and total sludge production grew by $13 \%$ annually from 2007 to 2013 (Yang et al., 2015). The spread of ARGs and ARB due to the release of the huge amounts of WAS should be emphasized (Munir et al., 2011; Singer et al., 2016).

Although antibiotic resistance could not be eradicated due to its ancient origins, it could be managed to limit the threat and minimize the impacts (United Kingdom Department of Health \& DEFRA, 2013), and WAS treatment technology could be the key point (Burch et al., 2014). Anaerobic digestion (AD) was widely used for the WAS treatment since it could economically and efficiently realize the resource utilization, volume reduction and harmless of WAS (Zhang et al., 2015). However, the rate-limiting step for the AD efficiency the slow hydrolysis, and thus sludge pretreatment to enhance the hydrolysis of WAS was obviously necessary. Microwave pretreatment (MW), especially with $\mathrm{H}_{2} \mathrm{O}_{2}$, was widely demonstrated to be able to enhance the cell destruction of WAS, which further availed the hydrolysis of WAS in AD, and volatile solids removal, methane production and $\mathrm{AD}$ stabilization were simultaneously improved (Liu et al., 2015a, b; Wang et al., 2009; Kuglarz et al., 2013).

A few studies have investigated the fate of ARGs during AD of WAS, and they suggested that AD could be used to reduce ARGs abundance (Zhang et al., 2016b; Ma et al., 2011), while our previous studies further confirmed that MW-WAS further facilitated ARGs reduction (Zhang et al., 2016b; Tong et al., 2016). However, it was indicated that the concentration of ARGs in AD effluents may not be directly related to the influent concentrations, because the presence of ARGs was influenced greatly by AD operating conditions and the composition of the microbial community (Miller et al., 2013; Ma et al., 2011; Youngquist et al., 2016), that is, the operating conditions of $\mathrm{AD}$ may be the primary factor that governed the composition of the bacterial community and the subsequent prevalence of ARGs (Youngquist et al., 2016). Additional research would be of value to determine the optimum AD conditions for removal of ARB or ARGs and to increase the understanding of the fate of ARGs during AD. Two-stage AD with hydrolytic acidification in the first stage and with methanogenesis in the second stage could enhance the methane production compared to onestage systems (Liu et al., 2016), but its effectiveness on the ARGs control needs to be investigated. Although Wu et al., (2016) investigated the influence of the two-phase AD of WAS on the fate of ARGs, they focused on the temperature in the different phase, while WAS pretreatment and the comparison between one-stage and two-stage systems concerning the ARGs control were unavailable.

Besides, it was also demonstrated that the co-selection from heavy metals caused by the cross- or co-resistance phenomena and horizontal gene transfer (HGT) through mobile genetic elements (MGEs) played an important role on the spread of ARGs in various environments (Pal et al., 2015; Riber et al., 2014; Xu et al., 2017). Considering the co-occurrence of significant amounts of heavy metals and antibiotics in WAS, the co-selection from heavy metals on the distribution of ARGs could not be negligible (Bondarczuk et al., 2016), while the immense biomass and intense interactions between the microorganisms provided the hotbed for the HGT of ARGs in WAS (Zhang et al., 2011). Thus, the investigation of the effects of co-selection from heavy metals and HGT on the ARGs profiles during AD would be of great importance.

In this study, three different $A D$ processes were established including the control (mono-WAS), one-stage AD (mono-MW) and two-stage AD (MW-Acid and MW-CH4) to (1) find out the different profiles of ARGs between one-stage and two-stage sludge $\mathrm{AD}$ comparing with the control (mono-WAS); (2) determine the relationship of the fate of ARGs and its potential drivers including bacterial community evolution, HGT through MGEs and coselection from heavy metals; (3) provide insight thoughts on the ARGs control during sludge AD.

\section{Material and methods}

\subsection{Sludge anaerobic digestion process}

The feed sludge was the dewatered WAS (total solids, TS, ca. 20\%) from the Qinghe WWTP, and then the dewatered WAS were diluted with deionized water to the TS concentration of ca. $8 \%$. Then, the sludge was stored at $4{ }^{\circ} \mathrm{C}$ and screened through 18mesh sieve before use and $\mathrm{MW}-\mathrm{H}_{2} \mathrm{O}_{2}$ pretreatment to remove the sands and other small inorganic matters existed in the WAS (Liu et al., 2015b; Liu et al., 2016b). The TS concentration of WAS after sieving was ca.7.6\%. The detailed $\mathrm{MW}-\mathrm{H}_{2} \mathrm{O}_{2}$ pre-treatment process was described elsewhere (Liu et al., 2015a). Briefly, $\mathrm{NaOH}$ solution at $5 \mathrm{M}$ was firstly added to adjust $\mathrm{pH}$ of the raw sludge to 10.0 , and then the sludge was heated to $80^{\circ} \mathrm{C}$ by microwave irradiation for inhibiting activity of catalase which is present in aerobic living cells to avoid the decomposition of $\mathrm{H}_{2} \mathrm{O}_{2}$ by the catalase that exists in the sludge (Liu et al., 2016a; Wang et al., 2009). After that, $\mathrm{H}_{2} \mathrm{O}_{2}(30 \%, w / w)$ was added at a dosage of $0.2 \mathrm{~g} \mathrm{H}_{2} \mathrm{O}_{2} /$ $\mathrm{g}$ TS as suggested previously (Wang et al., 2009). Finally, the sludge was continuously heated to $100{ }^{\circ} \mathrm{C}$ with microwave irradiation operating at $600 \mathrm{~W}$ and ambient pressure. The pretreatment process was carried out in $1 \mathrm{~L}$ beakers with plastic cap but was not sealed. $300 \mathrm{~mL}$ of waste activated sludge in the beaker was heated at the rate of $20^{\circ} \mathrm{C} / \mathrm{min}$ to reach the target temperature, not holding at 80 or $100^{\circ} \mathrm{C}$.

Three mesophilic sludge AD reactors were established in 2-L glass bottles with $1.8 \mathrm{~L}$ of effective working volume and equipped with a motor and stirring paddle each. All of the reactors operated semi-continuously, and the activated sludge or pretreated sludge with TS of approximately $8 \%$ was fed into the reactors once per day as previously reported (Liu et al., 2016a). Briefly, one was fed with WAS without pretreatment as the control (mono-WAS). Another was fed with a mixture of $\mathrm{MW}-\mathrm{H}_{2} \mathrm{O}_{2}$ pretreated sludge and raw sludge $\left(\right.$ Mass pretreated sludge $\left./ \mathrm{Mass}_{\text {raw sludge }}=1 / 1\right)$. Additionally, a two-stage reactor was set up with a $0.65 \mathrm{~L}$ bottle (the first stage reactor) in series with a $2 \mathrm{~L}$ bottle (the second stage reactor). The first stage reactor (MW-Acid) was fed with the mixture of $\mathrm{MW}-\mathrm{H}_{2} \mathrm{O}_{2}$ pretreated sludge and raw sludge, and the discharged sludge was fed into the second stage reactor $\left(\mathrm{MW}-\mathrm{CH}_{4}\right)$. MW$\mathrm{H}_{2} \mathrm{O}_{2}$ was adopted due to its most effective on the enhancement of the release of soluble substances in waste activated sludge compared with other MW combined process (Wang et al., 2009), while two-stage sludge $\mathrm{AD}$ was used to reduce the inhibitory effects of $\mathrm{H}_{2} \mathrm{O}_{2}$ on the biogas production as suggested previously (Liu et al., 2015a), and the first stage reactor was used for the preacidification of the feed sludge. The three digesters were 
manipulated in the same SRT and an organic loading rate (OLR) of approximately $2.92 \mathrm{~g}$ Volatile Solids (VS)/(L.d), and the detail anaerobic digesters operational parameters were listed in Table 1. The produced biogas was automatically recorded by an AMPTS II instrument (Bioprocess Control Company, Sweden). The ARGs and microbial community profiles were investigated during all the digesters were operated at optimal steady-state performance in terms of biogas production.

\subsection{Sampling and genomic DNA extraction}

Samples collected in this study included the feed sludge, pretreated sludge by $\mathrm{MW}-\mathrm{H}_{2} \mathrm{O}_{2}$ and the digested sludge of the three digesters, as well as the discharged sludge from the reactor of the MW-Acid, when the reactors were in stable operation for three solid retention times (SRT), about 90 days after startup. Sampling was continuously conducted for three days, and the three samples were then mixed to get a representative sample. There were six samples in total, including feed sludge as influent (IS), pretreated sludge by $\mathrm{MW}-\mathrm{H}_{2} \mathrm{O}_{2}$ (MW), the effluent of mono-WAS, monoMW, MW-Acid and MW-CH $\mathrm{CH}_{4} 1 \mathrm{~mL}$ sludge sample was centrifuged at $10,000 \mathrm{rpm}$ for $10 \mathrm{~min}$, and the pellet was used for DNA extraction using a FastDNA SPIN Kit for Soil (MP Biomedicals, USA) according to the manufacturer's instructions. DNA extraction of each sample was conducted in triplicate, and the triplicate DNA extracts were then merged together for further analysis. Extracted genomic DNA was detected and quantified using $1 \%$ agarose gel electrophoresis and NanoDrop 2000 (Thermo Scientific, USA), respectively, and then stored at $-20^{\circ} \mathrm{C}$ before use.

\subsection{Quantitative PCR ( $q P C R$ )}

Eleven frequently detected ARGs encoding resistance to $\beta$ lactam (bla $a_{\mathrm{OXA}-1}$ and $b l a_{\mathrm{TEM}}$ ), macrolides (ereA, ermB, ermF and $m e f A / E$ ), sulfonamides (sulI and sulII) and tetracyclines (tetG, tetM and tetX) were quantified. These ARGs were selected according to types of antibiotics and main resistance mechanisms (antibiotic deactivation or degradation, efflux pump and target protection) (Selvam et al., 2012). The class I integrase gene (intI1) was monitored as an indicator of horizontal gene transfer (HGT) and multiple antibiotic resistance (Amos et al., 2015; Gillings et al., 2014). While the three MRGs ( $p c o A$ and $c o p A$ encoding resistance to copper, $c z c A$ encoding resistance to cadmium, cobalt and zinc) represent the changes of heavy metals selective pressure during the process. Zinc and copper were selected due to its dominant presence in WAS in China (Zhang et al., 2016c) and its widely demonstrated co-selection for antibiotic resistance in various environments (Di Cesare et al., 2016; Garner et al., 2016; Xu et al., 2017). The changes of 16S rRNA gene copies were followed to represent the evolution of microbial biomass. The detail information of qPCR cycle conditions was described in Supporting information. The primers, annealing temperature and amplification efficiencies in this study were summarized in Table S1 and S2.

\subsection{High-throughput sequencing and bioinformatics analysis}

In order to gain insights into the potential mechanisms driving ARGs profiles, bacterial community was studied in detail through high-throughput sequencing method. The bacterial community was investigated using the PCR primers 515F and 806R targeting the 16S rRNA V4 region, which has been demonstrated to better reveal the bacterial community composition compared to other primers (Caporaso et al., 2010; Peiffer et al., 2013). The amplicons sent for small-fragment library construction and pair-end sequencing were prepared as previously described (Zhang et al., 2016a), and the high-throughput sequencing was done by Majorbio Co., Ltd., in Shanghai using the Illumina MiSeq sequencing system (Illumina, USA).

The detail bioinformatics analysis was conducted as suggested previously (Zhang et al., 2016a). Briefly, sequencing reads were assigned to each sample according to the unique barcode, and pair-end reads were merged using FLASH (Magoč and Salzberg, 2011), and then were filtered using QIIME quality filters $(r=3$, $\mathrm{p}=0.75, \mathrm{q}=3, \mathrm{n}=0$ ): ( $\mathrm{r}$ ) max_bad_run_- length: maximum number of consecutive low-quality base calls allowed before truncating a read; (p) min_per_read_length: mini- mum number of consecutive high-quality base calls to retain a read (as a percentage of total read length); (q) phred_quality_score: last quality score considered low quality; (n) sequence_max_n: maximum number of ambiguous $(\mathrm{N})$ characters allowed in a sequence. PCR chimeras were filtered out using UCHIME (Edgar et al., 2011). To fairly compare the samples at the same sequencing depth, the sequence number was normalized by extracting the first 29,269 from each sample for further analysis, and then the normalized sequences were uploaded to MG-RAST (http://metagenomics.anl.gov/linkin.cgi? project=17628). The sequences were also submitted to the NCBI Sequence Read Archive (SRA) under the project number of PRJNA387350.

The taxonomic classification of the sequences was carried out using the RDP Classifier selecting the gene bacterial 16S in the RDP pipeline, and the confidence cutoff was set as $50 \%$ as suggested by the RDP (Wang et al., 2007). Potential pathogens were identified according to the virulence factor database (VFDB) at the taxonomy level of genera (Chen et al., 2016). In addition, diversity and richness indices were calculated using the Rarefaction, Shannon Index and Chao1 estimator in the pipeline.

\subsection{Data analysis}

The absolute copy numbers indicated the relevant gene copies per unit of dry weight (DW), while the relative abundance was calculated through the normalized gene copies by $16 \mathrm{~S}$ rRNA. The significance of the correlation between ARGs, MRGs and intI1 was checked by SPSS 21.0 (IBM, USA), and a $p$ value $<0.05$ was considered statistically significant. Principal component analysis (PCA), redundancy analysis (RDA) and procrustes analysis were conducted by Canoco 5.0 (Microcomputer Power, USA), and mantel test was done through PAST 3.07 (Hammer et al., 2001). The heat maps in this study were built by Heml 1.0 (Deng et al., 2014).

Table 1

The detail operational parameters in different digesters.

\begin{tabular}{|c|c|c|c|c|c|c|c|}
\hline Process & SRT (d) & Feed & $\mathrm{T}\left({ }^{\circ} \mathrm{C}\right)$ & Working volume & TS & VS & OLR $(\mathrm{g} \mathrm{VS} /(\mathrm{L} \cdot \mathrm{d}))$ \\
\hline Mono-WAS & 20 & Untreated sludge & $37^{\circ} \mathrm{C}$ & $1.8 \mathrm{~L}$ & $6.00 \pm 0.04 \%$ & $3.73 \pm 0.05 \%$ & 2.89 \\
\hline Mono-MW & 20 & Mixture $^{a}$ & $37^{\circ} \mathrm{C}$ & $1.8 \mathrm{~L}$ & $5.54 \pm 0.01 \%$ & $3.16 \pm 0.03 \%$ & 2.87 \\
\hline MW-Acid & 2 & Mixture $^{a}$ & $37^{\circ} \mathrm{C}$ & $0.18 \mathrm{~L}$ & $6.70 \pm 0.18 \%$ & $4.90 \pm 0.17 \%$ & $28.65^{c}$ \\
\hline $\mathrm{MW}-\mathrm{CH}_{4}$ & 18 & Discharge of MW-Acid & $37^{\circ} \mathrm{C}$ & $1.62 \mathrm{~L}$ & $5.50 \pm 0.03 \%$ & $3.12 \pm 0.04 \%$ & $2.72^{\mathrm{c}}$ \\
\hline
\end{tabular}

a Mass $_{\text {pretreated sludge }} /$ Mass $_{\text {raw sludge }}=1 / 1$.

b The VS loss during the first stage was ca. 3.6\%.

c The OLR of the whole two-stage system was $2.87 \mathrm{~g} \mathrm{VS/(L \cdot d).}$ 


\section{Results and discussion}

3.1. Effects of $\mathrm{MW}-\mathrm{H}_{2} \mathrm{O}_{2}$ pretreatment on reduction of $A R G$ quantities and abundance

MW- $\mathrm{H}_{2} \mathrm{O}_{2}$ could reduce all the ARGs quantities especially for ermB, ermF, bla $\mathrm{OXA}_{-1}$ and tetX as shown in Fig. 1. The total ARGs quantities decreased by $0.70 \operatorname{logs}$, and also the biomass reflected by the $16 \mathrm{~S}$ rRNA gene copies was reduced by 1.22 logs. Interestingly, the change of the abundance of ARGs varied significantly (Fig. 2). MW- $\mathrm{H}_{2} \mathrm{O}_{2}$ increased the abundance of most ARGs except erm $B$ and tet $X$, and the mefA/E increased the most in abundance by 16.4 times. The total ARGs relative abundance was increased by 3.41 times.

The decrease of ARGs gene copies after $\mathrm{MW}-\mathrm{H}_{2} \mathrm{O}_{2}$ (Fig. 1) was associated with the death of live microbes and destruction of their DNA due to the heating effects reflected by the reduction of microbial biomass, while the increase of ARGs relative abundance (Fig. 2) indicated that ARGs may resist the degradation caused by the $\mathrm{MW}-\mathrm{H}_{2} \mathrm{O}_{2}$, and it seemed like that host bacteria of ARGs were more prone to surviving from MW- $\mathrm{H}_{2} \mathrm{O}_{2}$. The dominant ARG was sulI (8.84 logs) in IS, and $b l a_{\mathrm{OXA}-1}$, the least (3.98 logs), while $\mathrm{MW}-\mathrm{H}_{2} \mathrm{O}_{2}$ did not changed the composition of ARGs significantly.

The gene copies and abundance of intI 1 both increased a lot after $\mathrm{MW}-\mathrm{H}_{2} \mathrm{O}_{2}$, and intI1 was the only target gene which not only increased in quantities by 0.18 logs but also increased the most in abundance by 25.4 times. This indicated the higher survival of class I integrons, which could explain its dominance in various environments (Gaze et al., 2011). As for MRGs, $c z c A$ was the dominant MRG (8.04 logs) followed by copA (6.88 logs) and pcoA (6.57 logs), and $\mathrm{MW}-\mathrm{H}_{2} \mathrm{O}_{2}$ could reduce MRGs by $0.64-0.89$ logs. However, the abundance of MRGs all increased significantly after $\mathrm{MW}-\mathrm{H}_{2} \mathrm{O}_{2}$ by 2.19-3.85 times with $c z c A$ increasing the most.

\subsection{Changes of absolute gene copies of ARGs during subsequent $A D$}

The microbial biomass increased significantly in all the subsequent $\mathrm{AD}$, along with MW-Acid increasing the most followed by $\mathrm{MW}-\mathrm{CH}_{4}$, mono-WAS and mono-MW (Fig. 1). Total ARGs quantities showed similar changes to microbial biomass, and there was significantly positive correlation between total ARGs and microbial biomass $(p<0.05)$. This indicated that the proliferation of microbes during AD inevitably led to the increase of ARGs quantities as suggested previously in various environments (Zhang et al., 2016a, b; Burch et al., 2013). Concerning each ARG quantities, there was some difference between the different digesters. The $b l a_{\mathrm{OXA}-1}$ deceased to $\mathrm{ND}$ in both $\mathrm{MW}-\mathrm{CH}_{4}$ and mono-MW, while it increased to $4.62 \operatorname{logs}$ in mono-WAS similar to MW-Acid. This may indicate that the host bacteria of $b l a_{\mathrm{OXA}-1}$ mainly belonged to the acid-forming bacteria. ARGs quantities were enriched by 1.05-4.95 logs after subsequent AD (Fig. 3), and two-stage sludge AD showed the least enrichment of bla $a_{\mathrm{TEM}}$, sulI, sulII, tetM and tetX; one-stage $\mathrm{AD}$, ereA, ermF and tetG; mono-WAS, ermB and mefA/E (Fig. 1). The ermB (4.23-4.95 logs) followed by ermF (3.083.83 logs) were enriched the most in each digester, while sull (1.04-1.37 logs) and tetG (1.10-1.40 logs) increased the least. The dominant ARGs also changed significantly, sull dominated in the feed, and its dominance did not change after MW. However, ermB (8.68-9.40 logs) and ermF (9.89-10.63 logs) dominated after AD (Fig. 1). This indicated that physical effects could not change the composition of ARGs much, and it may be the changes of microbial community caused by the environmental conditions that at last changed the composition.

The intI1 and MRGs gene copies also increased significantly after AD. The intI1 increased by 2.21-2.55 logs with two-stage sludge anaerobic digestion enriching the least followed by monoMW and mono-WAS (Fig. 1). The $c z c A$ was still the dominant MRG, and it was enriched the most in all digesters after AD.

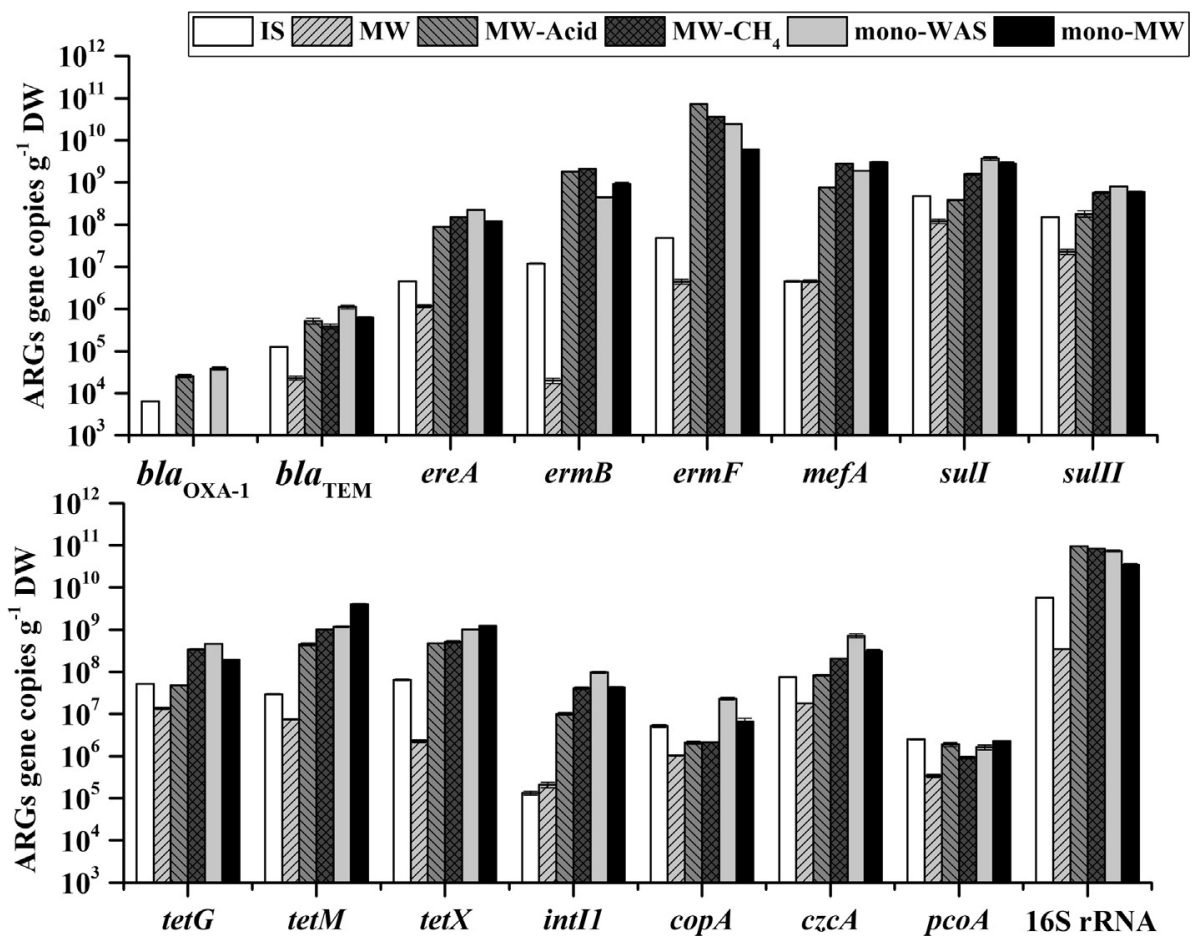

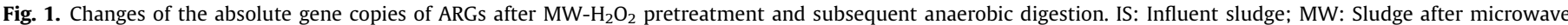

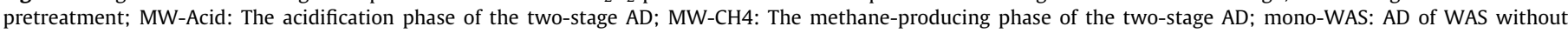
pretreatment; mono-MW: AD of WAS along with $\mathrm{MW}-\mathrm{H}_{2} \mathrm{O}_{2}$ pretreatment. 

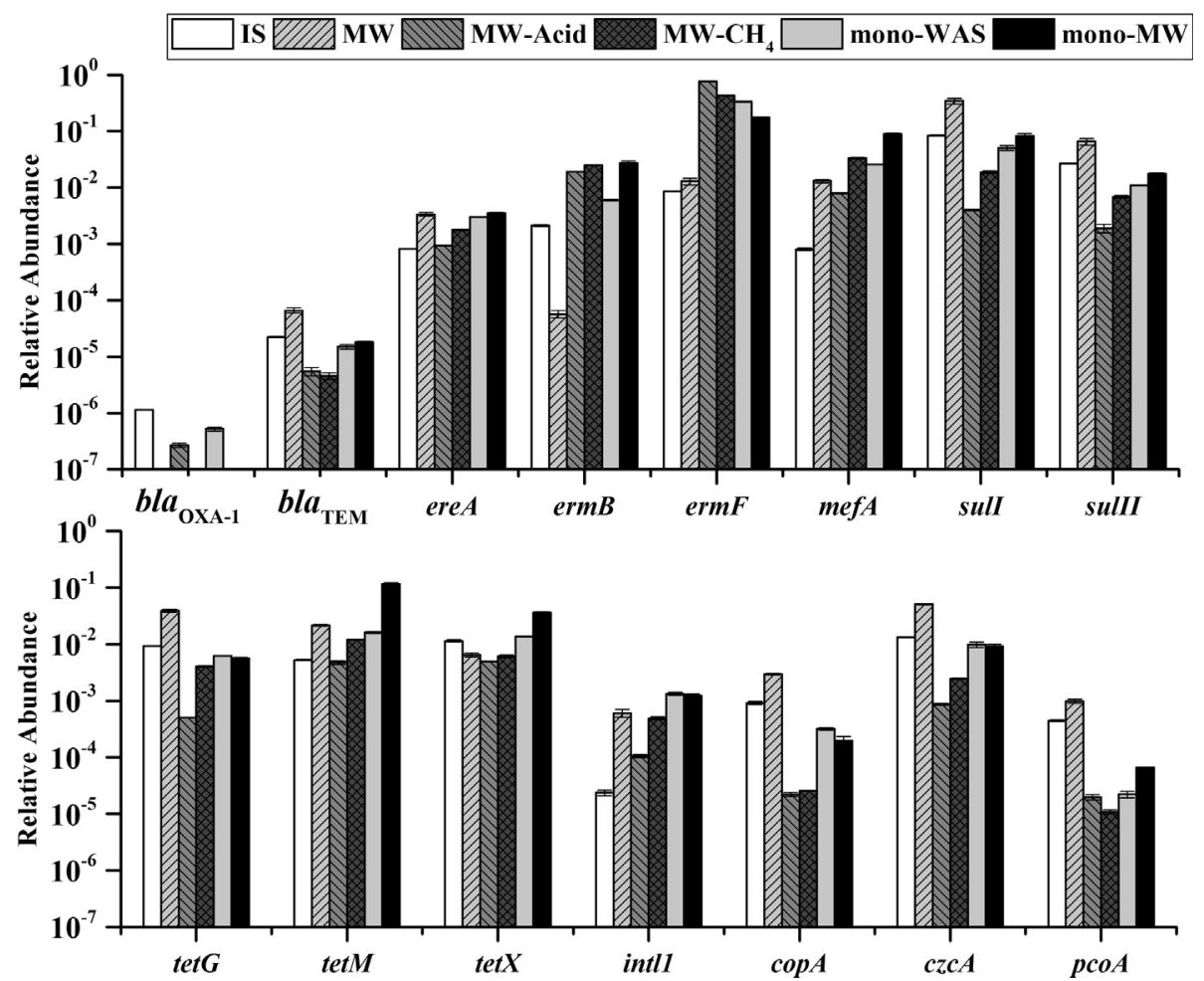

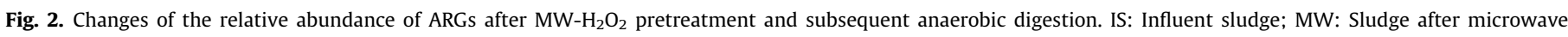

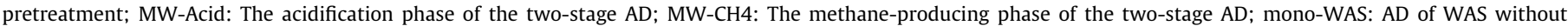
pretreatment; mono-MW: AD of WAS along with $\mathrm{MW}-\mathrm{H}_{2} \mathrm{O}_{2}$ pretreatment.

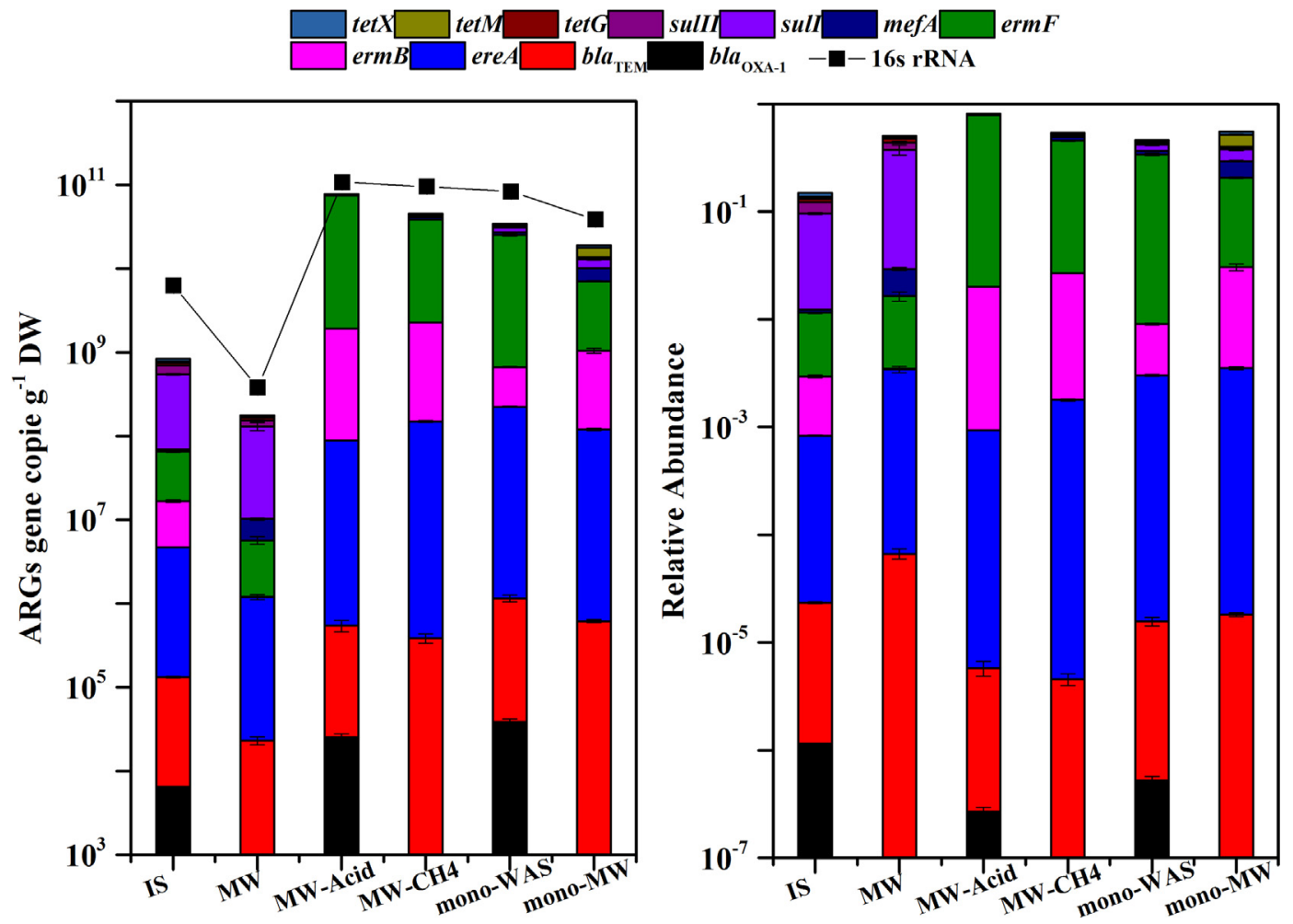

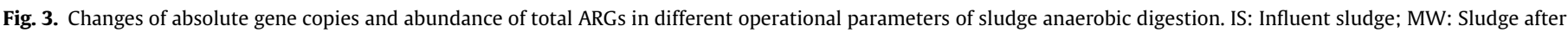

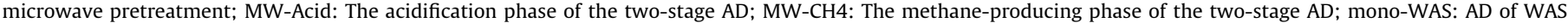
without pretreatment; mono-MW: AD of WAS along with $\mathrm{MW}-\mathrm{H}_{2} \mathrm{O}_{2}$ pretreatment.

Two-stage sludge AD enriched the least (0.25-0.99 logs) MRGs (Fig. 1). Together, MW- $\mathrm{H}_{2} \mathrm{O}_{2}$ subsequent AD increased all the target genes due to the increase of microbial biomass as reflected by $16 \mathrm{~S}$
rRNA gene copies. Two-stage sludge AD showed slight advantage on ARGs quantities control due to the less enrichment of intI1, MRGs and more kinds of ARGs compared with mono-MW. 


\subsection{Reduction of the abundance of ARGs during subsequent $A D$}

The Normalizing ARGs gene copies to 16S rRNA genes copies, as indicated by the relative abundance, could not only correct for the variations in extraction efficiencies and analytical efficiencies but also provide an indicator of the proportion of bacteria carrying ARGs (Knapp et al., 2010; McKinney et al., 2010), and it was crucial to determine the changes of relative abundance of ARGs during AD of WAS. Total ARGs abundance was further enriched slightly (1.64 and1.69 times for two-stage $A D$ and one-stage $A D$, respectively) along with mono-WAS increased the most (3.12 times). This indicated that $\mathrm{MW}-\mathrm{H}_{2} \mathrm{O}_{2}$ pre-treatment availed the ARGs control in sludge AD. As shown in Fig. 2, AD reduced the abundance of bla $a_{\mathrm{TEM}}$, sulI, sulII and tet $G$ in all the digesters, while ereA, tetM and tetX only in two-stage AD. Two-stage AD could reduce more kinds of ARGs abundance. The erm $B$, erm $F$ and $m e f A / E$ were enriched in all the digesters, and $\operatorname{erm} B$ was enriched the most especially in two-stage AD (439.13 times) followed by ermF (33.46 times). The significant increase of erm $B$, erm $F$ and $m e f A / E$ during sludge anaerobic digestion has been elucidated previously (Zhang et al., 2016b). The reason may be that host bacteria of these ARGs functioned necessarily during $A D$, which indicated that the enrichment of these ARGs just elucidated the special proliferation of the host bacteria. Previous study suggested that antibiotics in WAS should be not enough to select for $A R B$ and pose the selective pressure for the balance of the fitness cost of ARBs (Youngquist et al., 2016). Sludge AD also supported that ARBs could be reduced effectively, while ARGs increased significantly after AD (Tong et al., 2016). We speculated that these host bacteria may not function as ARB at all, instead, its primary function was for biogas production, that is, although, ARGs like ermB, ermF and $m e f A / E$ were enriched, the risks of these ARGs may be reduced after AD. As for the highest ARGs concentrations in MW-Acid, it was attributed that the fast proliferation for the acid-production microbes compared to the methogens, and this has been proved by the highest $16 \mathrm{~s}$ rRNA gene copies in the MW-Acid. The highest abundance of ARGs in the MW-Acid could be because of that the host of ARGs could also function as the important acid-production microbes, and the accumulation of ARGs, especially in the extracellular DNA, could not be overlooked.

Mobile genetic elements like Class I integrons (intI1), were often used to represent the HGT and multiple antibiotic resistance (Dang et al., 2017). Although they cannot mobilize and transfer themselves between microbes, they are often associated with mobile genetic elements which can, such as conjugative plasmids and insertion sequences (Berglund, 2015). Thus, intI1 was suggested as the proxy for anthropogenic pollution of ARGs (Gillings et al. 2014). Two-stage AD could reduce the abundance of intI1, while mono-MW and mono-WAS enriched it by 2.06 and 55.60 times, respectively. This may indicate that two-stage could reduce some risks from ARGs, and mono-WAS without $\mathrm{MW}-\mathrm{H}_{2} \mathrm{O}_{2}$ showed the highest risks concerning HGT. Each MRG abundance was decreased a lot, and this was comparable with previous study, which indicated that MRGs could be reduced due to the passivation of heavy metals in AD (Zhang et al., 2016b).

Above all, the relative abundance of MRGs was reduced after AD in all the digesters. Some ARGs relative abundance including bla $_{\mathrm{TEM}}$, sulI, sulII and tet $G$ were reduced after $\mathrm{AD}$, while intI1 was reduced only in two-stage $\mathrm{AD}$, and ermB and erm $F$ were enriched the most whatever the quantities and relative abundance. Besides, two-stage AD reduced more types of ARGs relative abundance.

\subsection{Bacterial community and potential pathogens}

According to the diversity and richness analysis, the diversity of MW-Acid was the lowest, and $\mathrm{MW}-\mathrm{CH}_{4}<$ mono-MW $<$ mono-WAS. Two-stage AD showed more specificity compared with monoWAS and mono-MW. The changes of bacterial community at the phylum level were shown in Fig. 4A. It showed that phylum Proteobacteria dominated in the feed, while Bacteroidetes dominated after $\mathrm{AD}$, and this corresponded to the sequential dominate of sulI and ermF. MW $-\mathrm{H}_{2} \mathrm{O}_{2}$ changed the bacterial community little, the dominant phylum was Proteobacteria (59.2\%) in the feed sludge followed by Bacteroidetes (14.8\%). After $\mathrm{MW}-\mathrm{H}_{2} \mathrm{O}_{2}$, the dominant phylum was the same, and the abundance of Proteobacteria and Bacteroidetes were $57.2 \%$ and $14.3 \%$, respectively. The little change in microbial composition could explain the small changes of prevalence ARGs in sludge, while Firmicutes increased from $4.6 \%$ to $9.7 \%$ and Actinobacteria from $4.9 \%$ to $7.8 \%$.

The dominant phylum changed significantly after AD as shown in Fig. 4A, Bacteroidetes become dominant in the three AD digesters accounting for $78.1 \%, 51.1 \%$ and $39.9 \%$ in two-stage $\mathrm{AD}$, one-stage $\mathrm{AD}$ and mono-WAS, respectively. Meanwhile, Proteobacteria
A

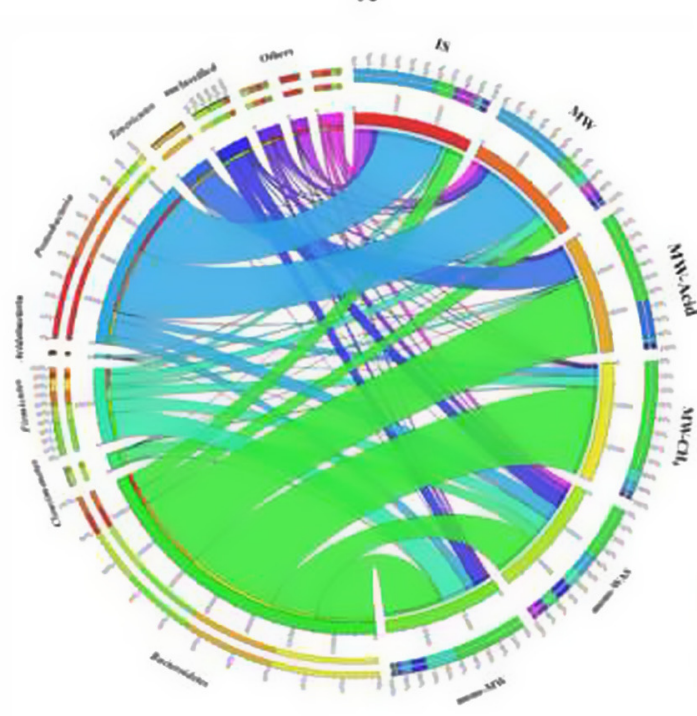

B

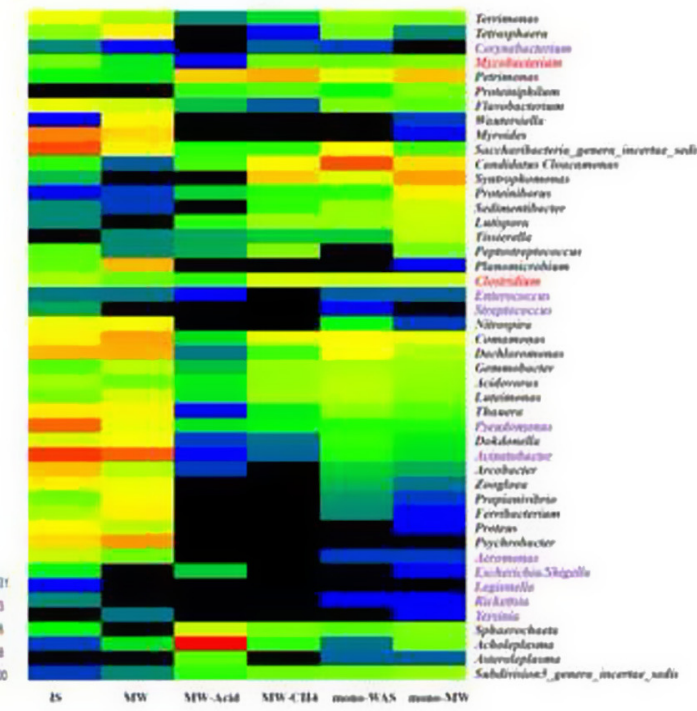

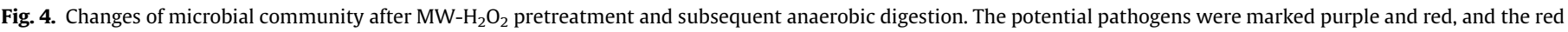
indicated that they should be more emphasized after anaerobic digestion. 
decreased to $7.3 \%, 7.9 \%$ and $13.8 \%$, respectively. The significant increase of Bacteroidetes abundance might explain the increase of erm $B$ and $e r m F$ abundance. It was speculated that the host bacteria of ermB and ermF which increased the most concerning the abundance mainly existed in Bacteroidetes (Liu and Pop, 2009), while the host bacteria of sulI, sulII, bla $a_{\mathrm{TEM}}$ and tetG mainly existed in Proteobacteria, and the reduction of these ARGs abundance might be associated with the changes of bacterial community. Firmicutes changed little after AD, except in mono-MW (23.3\%). Also Tenericutes $(26.5 \%)$ was only dominant in MW-Acid.

In order to elucidate the changes of bacterial community in detail, the first top ten genera, the genera abundance above $1 \%$ and potential pathogens were selected in each sample (Fig. 4B). Acinetobacteria belonging to Proteobacteria was the dominant genera in both IS (13.4\%) and MW (8.4\%), and it has been demonstrated to be the host bacteria of over 41 kinds of ARGs including sulI, bla $a_{\mathrm{TEM}}$, tetG and tetM (Liu and Pop, 2009). It was speculated that the dominance of sull may be associated with Acinetobacteria. While Acinetobacteria decreased to below $0.01 \%$ in all the digesters after $A D$, corresponding the reduction of the abundance of sulI, $b l a_{\mathrm{TEM}}$, tet $G$ and tetM. Concerning the dominant genera after AD, unfortunately, $69.4 \%-83.1 \%$ sequences could not be classified to the genus due to the limited dataset and technology compared with IS (23.8\%) and MW (35.4\%), and the unclassified sequences mainly belonged to the phylum of Bacteroidetes. Petrimonas (3.5\%), Cloacamonas (10.3\%) and Syntrophomonas (4.1\%) were the identified dominant genus in $\mathrm{MW}-\mathrm{CH}_{4}$, mono-WAS and mono$\mathrm{MW}$, respectively. As shown in Fig. $5, \mathrm{MW}-\mathrm{H}_{2} \mathrm{O}_{2}$ changed the bacterial community little as demonstrated by PcoA, while the difference of the bacterial community after $A D$ between different digesters was distinct (Fig. 5).

According to the VFDB, 12 genera were classified to the potential pathogens in the feed sludge (Fig. 4B). MW- $\mathrm{H}_{2} \mathrm{O}_{2}$ could reduce them to some extent, while $\mathrm{AD}$ could reduce them more effectively. For instance, the dominant potential pathogens in IS were Acinetobacter and Pseudomonas, and $\mathrm{MW}-\mathrm{H}_{2} \mathrm{O}_{2}$ decreased the abundance from $13.4 \%$ to $8.4 \%$ and $8.2 \%$ to $1.1 \%$, respectively, while AD could reduce them to below $0.01 \%$. However, some potential pathogens rebound after $\mathrm{AD}$, like Clostridium and Mycobacterium, and $\mathrm{MW}-\mathrm{H}_{2} \mathrm{O}_{2}$ could reduce them from $0.51 \%$ and $0.26 \%$ to $0.24 \%$ and $0.05 \%$, respectively, while they both rebound to $0.74 \%-0.86 \%$ and $0.21 \%-0.3 \%$, respectively. This indicated that these genera should be paid more attention after $\mathrm{AD}$.

\subsection{Relationship among ARGs, bacterial community, intI1 and MRGs}

In order to figure out the relationship between evolution of ARGs and changes of bacterial community, procrustes analysis was conducted as suggested previously (Zhang et al., 2016a,b). The results indicated there existed significantly positive correlation between them (Fig. 5). Changes of bacterial community accounted for the $86.6 \%$ of the variation of ARGs abundance, and the correlation between the two axes was significantly positive ( $\mathrm{R}=0.9750$ and 0.9436 , respectively). A Mantel test based on Bray-Curtis distance confirmed the significantly positive correlation between them $(R=0.7436, p=0.0001$, permutation $\mathrm{N}=9999$ ). This indicated that bacterial community contributed significantly to the evolution of ARGs during these treatments. This kind of relationship between ARGs and bacterial community has been established in various environments (Li et al., 2015; Zhang et al., 2016b).

The class I integron plays an important role in gene transfer among bacteria. There is no significantly positive correlation between intI1 and ARGs increased except ereA $(p=0.042)$ (Table S3). This may indicate that the role of mobile genetic elements on the occurrence of ARGs during AD was limited. MRGs
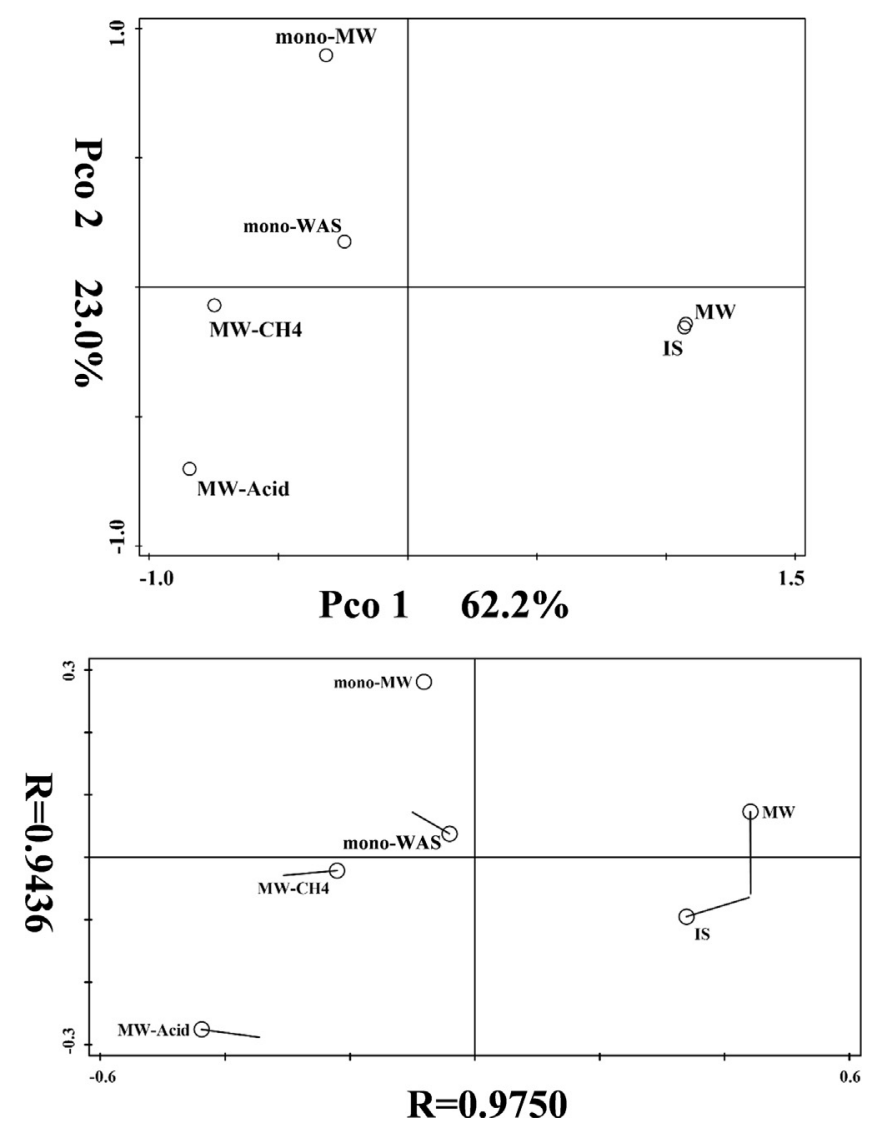

Fig. 5. PcoA and procrustes analysis based on OTUs and ARGs evolution.

could reflect the real response of bacteria to the selective pressures of heavy metals better compared with the concentration of heavy metals. There was significantly positive correlation between sull, sulII, tet $G$ and $b l a_{\text {TEM }}$ and MRGs which decreased significantly after AD. This may indicate that the reduction of heavy metals selective pressure facilitate these ARGs reduction during $A D$, which was favoured previously in AD (Zhang et al., 2016b).

RDA analysis was conducted to investigate the relationships between bacterial community, intI1 and MRGs and ARGs (Fig. 6), and the results showed that the selected variables accounted for $94.9 \%$ of the total variation of the evolution of ARGs quantified in this study. The primary contributors for the different ARGs profiles in different stages varied significantly (Fig. 6). Firmicutes and intI1 mainly accounted for the evolution of the ARGs including tetX, $m e f A / E$, tetM and ereA, while Bacteroidetes mainly accounted for the evolution of ermB and ermF, and MRGs were associated with the abundance reduction of sull, sulII, tetG and bla $a_{\mathrm{TEM}}$. Besides, there existed significantly positive correlations between potential pathogens including Acinetobacter, Aeromonas, Enterococcus and Pseudomonas and ARGs which decreased including sull, sulII, tetG and $b a_{\mathrm{TEM}}$. This indicated that the pathogens reduction due to AD contributed to the ARGs reduction. However, the potential pathogens including Clostridium and Mycobacterium which increased after $A D$ should be paid more attention, because they have been demonstrated to host bacteria of the 23 and 8 resistance gene types, respectively, including ermB, ermF and mefA/E which increased significantly after AD in this study.

It looks like that ARGs after AD was only associated with the operation parameters not the feed sludge. The results suggested that bacterial community composition of the sludge digestion process drives the profiles of ARGs, rather than the influent ARG composition. The role of intI 1 may be also limited during AD especially 


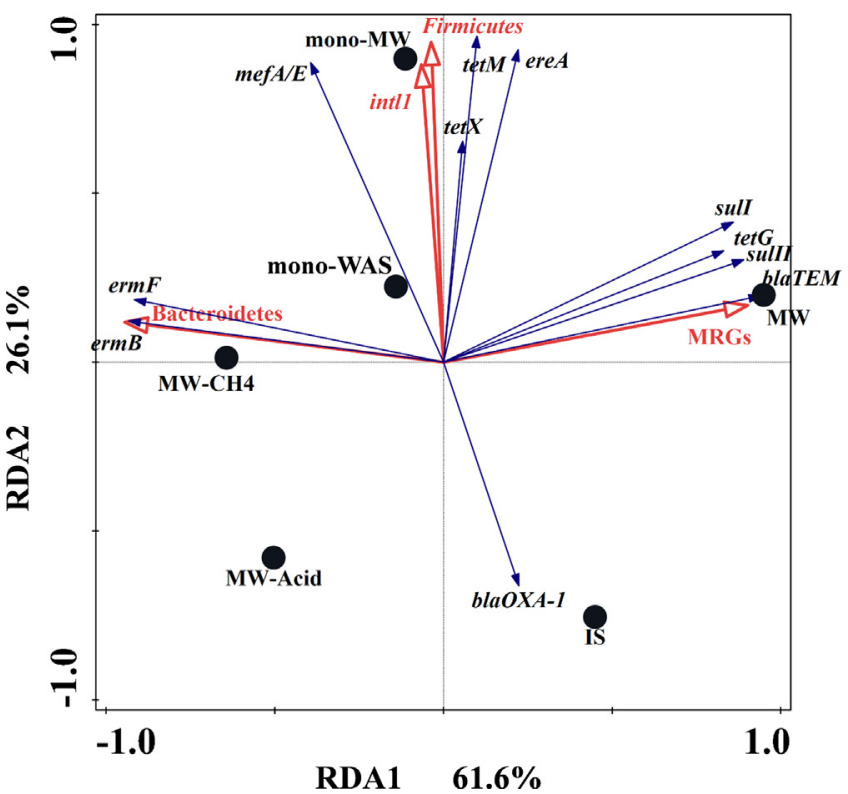

Fig. 6. RDA analysis based on bacterial community, intI1, MRGs and ARGs evolution. ARGs were treated as species variable, and others were treated as environmental variables.

in two-stage $\mathrm{AD}$, and the evolution of ARGs was mainly associated with the changes of bacterial community. Concerning the risks of ARGs, we should not only consider the amount of ARGs but also the role of MGEs and co-selection from heavy metals, and from the respective of this, AD was a potential technology for the ARGs control during sludge treatment. Besides, it was demonstrated that thermophilic system outperform than mesophilic system for ARGs removal, and the role of temperature on the ARGs profiles and drivers of the one-stage and two-stage systems deserve further investigation.

\section{Conclusions}

The potential of sludge AD for ARGs control through $\mathrm{MW}-\mathrm{H}_{2} \mathrm{O}_{2}$ was investigated in different operational parameters. $\mathrm{MW}-\mathrm{H}_{2} \mathrm{O}_{2}$ along with subsequent $\mathrm{AD}$ could realize some control on ARGs abundance. Two-stage AD showed some advantages on the ARGs abundance reduction and enriched the least ARGs quantities. $\mathrm{MW}-\mathrm{H}_{2} \mathrm{O}_{2}$ could reduce gene copies of all ARGs while increased the abundance of most ARGs. AD enriched both total ARGs gene copies and abundance while ARGs associated with MRGs were reduced. AD could reduce the role of intI1 on the spread of ARGs, and the ARGs proliferation was closely related with the evolution of microbial community.

\section{Conflict of interest}

The authors declare no conflict of interest.

\section{Acknowledgements}

This work was supported by the National Major Science \& Technology Projects for Water Pollution Control and Management of China (2012ZX07202-005, 2015ZX07203-005) and the State Key Joint Laboratory of Environmental Simulation and Pollution Control of China (16Z04ESPCR).

\section{Appendix A. Supplementary data}

Supplementary data associated with this article can be found, in the online version, at http://dx.doi.org/10.1016/j.biortech.2017.05. 157.

\section{References}

Amos, G.C., Gozzard, E., Carter, C.E., Mead, A., Bowes, M.J., Hawkey, P.M., Zhang, L., Singer, A.C., Gaze, W.H., Wellington, E.M.H., 2015. Validated predictive modelling of the environmental resistome. ISME J. 9, 1467-1476. http://dx. doi.org/10.1038/ismej.2014.237.

Berglund, B., 2015. Environmental dissemination of antibiotic resistance genes and correlation to anthropogenic contamination with antibiotics. Infect. Ecol. Epidemiol. 5, 28564.

Bondarczuk, K., Markowicz, A., Piotrowska-Seget, Z., 2016. The urgent need for risk assessment on the antibiotic resistance spread via sewage sludge land application. Environ. Int. 87, 49-55. http://dx.doi.org/10.1016/j. envint.2015.11.011.

Burch, T.R., Sadowsky, M.J., Lapara, T.M., 2014. Fate of antibiotic resistance genes and class 1 integrons in soil microcosms following the application of treated residual municipal wastewater solids. Environ. Sci. Technol. 48, 5620-5627.

Burch, T.R., Sadowsky, M.J., LaPara, T.M., 2013. Air-drying beds reduce the quantities of antibiotic resistance genes and class 1 integrons in residual municipal wastewater solids. Environ. Sci. Technol. 47, 9965-9971. http://dx.doi.org/ 10.1021/es4024749.

Caporaso, J.G., Lauber, C.L., Walters, W.A., Berg-Lyons, D., Lozupone, C.A., Turnbaugh, P.J., Fierer, N., Knight, R., 2010. Global patterns of 16S rRNA diversity at a depth of millions of sequences per sample. In: PNAS 108, 1516-1522. http://dx.doi org/10.1073/pnas.1000080107/-/DC.

Chen, L., Zheng, D., Liu, B., Yang, J., Jin, Q., 2016. VFDB 2016: hierarchical and refined dataset for big data analysis-10 years on. Nucleic Acids Res. 44, D694-D697. http://dx.doi.org/10.1093/nar/gkv1239.

Dang, B., Mao, D., Xu, Y., Luo, Y., 2017. Conjugative multi-resistant plasmids in Haihe River and their impacts on the abundance and spatial distribution of antibiotic resistance genes. Water Res. 111, 81-91. http://dx.doi.org/10.1016/j. watres.2016.12.046.

Deng, W., Wang, Y., Liu, Z., Cheng, H., Xue, Y., 2014. HemI: a toolkit for illustrating heatmaps. PLoS One 9, e111988. http://dx.doi.org/10.1371/journal. pone.0111988.

Di Cesare, A., Eckert, E.M., D'Urso, S., Bertoni, R., Gillan, D.C., Wattiez, R., Corno, G., 2016. Co-occurrence of integrase 1 , antibiotic and heavy metal resistance genes in municipal wastewater treatment plants. Water Res. 94, 208-214. http://dx. doi.org/10.1016/j.watres.2016.02.049.

Edgar, R.C., Haas, B.J., Clemente, J.C., Quince, C., Knight, R., 2011. UCHIME improves sensitivity and speed of chimera detection. Bioinformatics 27, 2194-2200. http://dx.doi.org/10.1093/bioinformatics/btr381.

Garner, E., Wallace, J.S., Argoty, G.A., Wilkinson, C., Fahrenfeld, N., Heath, L.S., Zhang, L., Arabi, M., Aga, D.S., Pruden, A., 2016. Metagenomic profiling of historic Colorado Front Range flood impact on distribution of riverine antibiotic resistance genes. Sci. Rep. 6, 38432. http://dx.doi.org/10.1038/srep38432.

Gaze, W.H., Zhang, L., Abdouslam, N.A., Hawkey, P.M., Calvo-Bado, L., Royle, J., Brown, H., Davis, S., Kay, P., Boxall, A.B.A., Wellington, E.M.H., 2011. Impacts of anthropogenic activity on the ecology of class 1 integrons and integronassociated genes in the environment. In: ISME J. 5, 1253-1261. http://dx.doi. org/10.1038/ismej.2011.15.

Gillings, M.R., Gaze, W.H., Pruden, A., Smalla, K., Tiedje, J.M., Zhu, Y.-G., 2014. Using the class 1 integron-integrase gene as a proxy for anthropogenic pollution. ISME J. 9, 1269-1279. http://dx.doi.org/10.1038/ismej.2014.226.

Hammer, Ø., Harper, D.A.T., Ryan, P.D., 2001. PAST: paleontological statistics software package for education and data analysis. Palaeontol. Electronica 4, 918. http://dx.doi.org/10.1016/j.bcp.2008.05.025.

Knapp, C.W., Dolfing, J., Ehlert, P.A.I., Graham, D.W., 2010. Evidence of increasing antibiotic resistance gene abundances in archived soils since 1940. Environ. Sci. Technol. 44, 580-587. http://dx.doi.org/10.1021/es901221x.

Kuglarz, M., Karakashev, D., Angelidaki, I., 2013. Microwave and thermal pretreatment as methods for increasing the biogas potential of secondary sludge from municipal wastewater treatment plants. Bioresour. Technol. 134 290-297. http://dx.doi.org/10.1016/j.biortech.2013.02.001.

Kumaraswamy, R., Amha, Y.M., Anwar, M.Z., Henschel, A., Rodr, J., Ahmad, F., 2014. Molecular analysis for screening human bacterial pathogens in municipal wastewater treatment and reuse. Environ. Sci. Technol. 48, 11610-11619.

Li, B., Yang, Y., Ma, L., Ju, F., Guo, F., Tiedje, J.M., Zhang, T., 2015. Metagenomic and network analysis reveal wide distribution and co-occurrence of environmental antibiotic resistance genes. ISME J. 9, 2490-2502. http://dx.doi.org/10.1038/ ismej.2015.59.

Liu, B., Pop, M., 2009. ARDB-antibiotic resistance genes database. Nucleic Acids Res. 37, 443-447. http://dx.doi.org/10.1093/nar/gkn656.

Liu, J., Jia, R., Wang, Y., Wei, Y., Zhang, J., Wang, R., Cai, X., 2015a. Does residual $\mathrm{H}_{2} \mathrm{O}_{2}$ result in inhibitory effect on enhanced anaerobic digestion of sludge pretreated by microwave- $\mathrm{H}_{2} \mathrm{O}_{2}$ pretreatment process? Environ. Sci. Pollut. Res. http://dx. doi.org/10.1007/s11356-015-5704-z. 
Liu, J., Tong, J., Wei, Y., Wang, Y., 2015b. Microwave and its combined processes: an effective way for enhancing anaerobic digestion and dewaterability of sewage sludge? J. Water Reuse Desalin. 5, 264. http://dx.doi.org/10.2166/wrd.2015.120.

Liu, J., Yu, D., Zhang, J., Yang, M., Wang, Y., Wei, Y., Tong, J., 2016a. Rheological properties of sewage sludge during enhanced anaerobic digestion with microwave- $\mathrm{H}_{2} \mathrm{O}_{2}$ pretreatment. Water Res. 98, 98-108. http://dx.doi.org/ 10.1016/j.watres.2016.03.073.

Liu, X., Wang, Y., Gui, C., Li, P., Zhang, J., 2016b. Chemical forms and risk assessment of heavy metals in sludge-biochar produced by microwave- induced low temperature pyrolysis. RSC Adv. 6, 101960-101967. http://dx.doi.org/10.1039/ C6RA22511J.

Ma, Y., Wilson, C.A., Novak, J.T., Riffat, R., Aynur, S., Murthy, S., Pruden, A., 2011. Effect of various sludge digestion conditions on sulfonamide, macrolide, and tetracycline resistance genes and class I integrons. Environ. Sci. Technol. 45, 7855-7861. http://dx.doi.org/10.1021/es200827t.

Magoč, T., Salzberg, S.L., 2011. FLASH: fast length adjustment of short reads to improve genome assemblies. Bioinformatics 27, 2957-2963. http://dx.doi.org/ 10.1093/bioinformatics/btr507.

Mao, D., Yu, S., Rysz, M., Luo, Y., Yang, F., Li, F., Hou, J., Mu, Q., Alvarez, P.J.J., 2015. Prevalence and proliferation of antibiotic resistance genes in two municipal wastewater treatment plants. Water Res. 85, 458-466. http://dx.doi.org/ 10.1016/j.watres.2015.09.010.

McKinney, C.W., Loftin, K. a, Meyer, M.T., Davis, J.G., Pruden, A., 2010. Tet and sul antibiotic resistance genes in livestock lagoons of various operation type, configuration, and antibiotic occurrence. Environ. Sci. Technol. 44, 6102-6109. http://dx.doi.org/10.1021/es9038165.

Miller, J.H., Novak, J.T., Knocke, W.R., Young, K., Hong, Y., Vikesland, P.J., Hull, M.S. Pruden, A., 2013. Effect of silver nanoparticles and antibiotics on antibiotic resistance genes in anaerobic digestion. Water Environ. Res. 85, 411-421. http://dx.doi.org/10.2175/106143012X13373575831394.

Munir, M., Wong, K., Xagoraraki, I., 2011. Release of antibiotic resistant bacteria and genes in the effluent and biosolids of five wastewater utilities in Michigan. Water Res. 45, 681-693. http://dx.doi.org/10.1016/j.watres.2010.08.033.

Pal, C., Bengtsson-palme, J., Kristiansson, E., Larsson, D.G.J., 2015. Co-occurrence of resistance genes to antibiotics, biocides and metals reveals novel insights into their co-selection potential. BMC Genomics 16, 964. http://dx.doi.org/10.1186/ s12864-015-2153-5.

Peiffer, J.A., Spor, A., Koren, O., Jin, Z., Tringe, S.G., Dangl, J.L., Buckler, E.S., Ley, R.E., 2013. Diversity and heritability of the maize rhizosphere microbiome under field conditions. PNAS 110, 6548-6553. http://dx.doi.org/10.1073/ pnas. 1302837110.

Riber, L., Poulsen, P.H.B., Al-soud, W.A., Hansen, L.B.S., Bergmark, L., Brejnrod, A., Norman, A., Hansen, L.H., Magid, J., Sørensen, S.J., 2014. Horizontal transfer of antibiotic resistance. FEMS Microbiol. Ecol. 90, 206-224. http://dx.doi.org/ 10.1111/1574-6941.12403.

Selvam, A., Xu, D., Zhao, Z., Wong, J.W.C., 2012. Fate of tetracycline, sulfonamide and fluoroquinolone resistance genes and the changes in bacterial diversity during composting of swine manure. Bioresour. Technol. 126, 383-390. http://dx.doi. org/10.1016/j.biortech.2012.03.045.

Singer, A.C., Shaw, H., Rhodes, V., Hart, A., Balcazar, J.L., 2016. Review of antimicrobial resistance in the environment and its relevance to environmental regulators. Front. Microbiol. 7. http://dx.doi.org/10.3389/ fmicb.2016.01728. Article 1728.

Su, J.Q., Wei, B., Ou-Yang, W.Y., Huang, F.Y., Zhao, Y., Xu, H.J., Zhu, Y.G., 2015. Antibiotic resistome and its association with bacterial communities during sewage sludge composting. Environ. Sci. Technol. 49, 7356-7363. http://dx.doi. org/10.1021/acs.est.5b01012.

Tong, J., Liu, J., Zheng, X., Zhang, J., Ni, X., Chen, M., Wei, Y., 2016. Fate of antibiotic resistance bacteria and genes during enhanced anaerobic digestion of sewage sludge by microwave pretreatment. Bioresour. Technol. 217, 37-43. http://dx. doi.org/10.1016/j.biortech.2016.02.130.

United Kingdom Department of Health \& DEFRA, 2013. UK Five Year Antimicrobial Resistance Strategy 2013 to 2018.

Wang, Q., Garrity, G.M., Tiedje, J.M., Cole, J.R., 2007. Naïve Bayesian classifier for rapid assignment of rRNA sequences into the new bacterial taxonomy. Appl. Environ. Microbiol. 73, 5261-5267. http://dx.doi.org/10.1128/AEM.00062-07.

Wang, Y., Wei, Y., Liu, J., 2009. Effect of $\mathrm{H}_{2} \mathrm{O}_{2}$ dosing strategy on sludge pretreatment by microwave- $\mathrm{H}_{2} \mathrm{O}_{2}$ advanced oxidation process. J. Hazard. Mater. 169, 680684. http://dx.doi.org/10.1016/j.jhazmat.2009.04.001.

Wu, Y., Cui, E., Zuo, Y., Cheng, W., Rensing, C., Chen, H., 2016. Influence of two-phase anaerobic digestion on fate of selected antibiotic resistance genes and class integrons in municipal wastewater sludge. Bioresour. Technol. 211, 414-421. http://dx.doi.org/10.1016/j.biortech.2016.03.086.

Xu, Y., Xu, J., Mao, D., Luo, Y., 2017. Effect of the selective pressure of sub-lethal level of heavy metals on the fate and distribution of ARGs in the catchment scale*. Environ. Pollut. 220, 900-908. http://dx.doi.org/10.1016/j.envpol.2016.10.074.

Yang, G., Zhang, G., Wang, H., 2015. Current state of sludge production, management, treatment and disposal in China. Water Res. 78, 60-73. http:// dx.doi.org/10.1016/j.watres.2015.04.002.

Youngquist, C.P., Mitchell, S.M., Cogger, C.G., 2016. Fate of antibiotics and antibiotic resistance during digestion and composting: a review. J. Environ. Qual. 45, 537545. http://dx.doi.org/10.2134/jeq2015.05.0256.

Zhang, J., Chen, M., Sui, Q., Tong, J., Jiang, C., Lu, X., Zhang, Y., Wei, Y., 2016a. Impacts of addition of natural zeolite or a nitrification inhibitor on antibiotic resistance genes during sludge composting. Water Res. 91, 339-349. http://dx.doi.org/ 10.1016/j.watres.2016.01.010.

Zhang, J., Chen, M., Sui, Q., Wang, R., Tong, J., Wei, Y., 2016b. Fate of antibiotic resistance genes and its drivers during anaerobic co-digestion of food waste and sewage sludge based on microwave pretreatment. Bioresour. Technol. 217, 2836. http://dx.doi.org/10.1017/CB09781107415324.004.

Zhang, J., Sui, Q., Tong, J., Buhe, C., Wang, R., Chen, M., Wei, Y., 2016c. Sludge biodrying: effective to reduce both antibiotic resistance genes and mobile genetic elements. Water Res. 106, 62-70. http://dx.doi.org/10.1017/ CB09781107415324.004.

Zhang, T., Yang, Y., Pruden, A., 2015. Effect of temperature on removal of antibiotic resistance genes by anaerobic digestion of activated sludge revealed by metagenomic approach. Appl. Microbiol. Biotechnol. 99, 7771-7779. http:// dx.doi.org/10.1007/s00253-015-6688-9.

Zhang, T., Zhang, X.-X., Ye, L., 2011. Plasmid metagenome reveals high levels of antibiotic resistance genes and mobile genetic elements in activated sludge. PLoS One 6, e26041. http://dx.doi.org/10.1371/journal.pone.0026041. 